\title{
Ecology of parasitically modified populations: a case study from a gammarid-trematode system
}

\author{
Fleur Ponton ${ }^{1, *}$, David G. Biron ${ }^{1}$, Cécile Joly ${ }^{1}$, Simone Helluy ${ }^{2}$, David Duneau ${ }^{1}$, \\ Frédéric Thomas ${ }^{1}$
}

\author{
${ }^{1}$ GEMI/UMR CNRS-IRD 2724, Equipe Evolution des Systèmes Symbiotiques, IRD, 911 Avenue Agropolis, BP 5045, \\ 34032 Montpellier Cedex 1, France \\ ${ }^{2}$ Department of Biological Sciences, Wellesley College, Wellesley, Massachusetts 02481, USA
}

\begin{abstract}
Examples of behavioural manipulation by parasites are numerous but the consequences of these phenomena on the ecology of host populations remains unclear. Through its effect on Gammarus insensibilis behaviour, the salt marsh trematode Microphallus papillorobustus splits its host population into 2 discrete subunits, one living at the surface (infected individuals) and the other living near the bottom (uninfected individuals). Here, we compare several biological characteristics of gammarids from these 2 spatially segregated subunits. Infected females were smaller and thus less fecund than uninfected females. They also had a longer intermoult duration. The mean body size of infected and uninfected males was not significantly different. However, energy reserves were significantly different: infected males possessed higher glycogen and lipid contents and lower glucose content compared to uninfected males. Interestingly, uninfected males living at the surface (those paired with infected females) also displayed higher energy reserves compared to uninfected conspecifics living in the bottom subunit (those paired with uninfected females). In both of the 2 subunits, there was no significant relationship between male sexual performance (measured through the size of their partner) and their levels of energy reserves. The pattern of size-assortative pairing was not significantly different between pairs from the surface and from the bottom, but male sexual performances were on average smaller for males from the surface subunit. Our results also indicated that the benefits of preferring large more fecund females are however likely to be counterbalanced by the higher mortality rate of these females compared to smaller ones during the subsequent intermoult. Because such a phenomenon directly influences the number of juveniles produced, it reduces the inequalities between the true sexual performances (i.e. number of descendants) achieved by males from the surface and from the bottom. This study supports the idea that infected gammarids are not simply normal hosts with an aberrant behaviour, they are more deeply modified in ways that may substantially alter host population ecology.
\end{abstract}

KEY WORDS: Parasitism $\cdot$ Host population $\cdot$ Trematode $\cdot$ Amphipod $\cdot$ Life history traits

\section{INTRODUCTION}

Over the past 15 to $20 \mathrm{yr}$, considerable progress has been made in understanding the functional importance of parasites on the ecology of host populations. Much empirical and theoretical evidence has demonstrated that parasites have the potential to interfere with processes as diverse as sexual selection (Hamil- ton \& Zuk 1982, Howard \& Minchella 1990, Clayton 1991, Moore \& Wilson 2002), population regulation (Anderson \& Gordon 1982, Thomas et al. 1995a, Rousset et al. 1996, Moller 2005), spatial distribution (Anderson 1972, Combes 1996, Torchin et al. 2003, Holt \& Boulinier 2005) and life history trait evolution (Hochberg et al. 1992, Forbes 1993, Lafferty 1993, Michalakis \& Hochberg 1994, Moller 1997, Agnew et 
al. 1999, Richner \& Triplet 1999). Although the literature is rife with examples of phenotypic alterations in parasitized organisms (Combes 1998, Poulin 1998, Moore 2002), little is known, however, concerning the more specific roles of manipulative parasites in these ecological processes. From an ecological point of view, manipulated hosts can be seen as complex organisms as they keep some of the properties and attributes of uninfected conspecifics but they also display new characteristics making them involved in new direct and indirect interactions with conspecifics and with other species (Thomas et al. 1998a, 1999, 2005a,b). Poulin \& Thomas (1999) argued that when the shift in phenotype caused by parasites is large, and when prevalence in the host population is less than $100 \%$, the distribution of trait values is likely to become bimodal, with parasitized and unparasitized individuals forming distinct groups. Despite theoretical expectations for parasites splitting host populations in such subunits, the importance of this phenomenon in natural conditions as well as its shortand long-term consequences on the functioning of host populations remain poorly understood (Poulin \& Thomas 1999).

The salt marsh trematode Microphallus papillorobustus has a complex life cycle, including snails from the genus Hydrobia as first intermediate hosts, gammaridean amphipods as second intermediate hosts, and various aquatic birds as definitive hosts (Rebecq 1964). Metacercariae of M. papillorobustus are always encysted in the brain (protocerebrum) of Gammarus insensibilis and induce strong behavioural alterations in this host, i.e. positive phototaxis, negative geotaxis, and an aberrant evasive behaviour making gammarids more vulnerable to predation by aquatic birds (Helluy 1981, 1984). Previous studies (e.g. Brun 1971, Helluy 1981, Thomas 1996) have demonstrated that this alteration in the host phenotype is so large that it actually splits the host population into 2 discrete subunits, infected and uninfected. Infected gammarids typically live at the surface of the water, while uninfected gammarids stay near the bottom (Helluy 1981, Thomas 1996). This spatial segregation has been shown to strongly interfere with the reproductive ecology of G. insensibilis (Thomas et al. 1995b). Mating in G. insensibilis occurs only during a narrow part of the female's moult cycle, usually within a few days or hours of the moult. Males which are able to identify females close to their moult, try to monopolize and guard them until fertilization of the eggs is possible. After insemination, the male generally guards the female for a few hours before abandoning her. Then, the eggs develop in the female's brood pouch during the intermoult period. In field populations of $G$. insensibilis, there is an assortative pairing by parasitism's presence/absence (i.e. uninfected males pair with uninfected females and infected males pair with infected females). A large part of this original pattern of pairing results from the vertical segregation between infected photophilic and uninfected photophobic individuals (Thomas et al. 1996a).

Besides this major influence on pair formation, little is known concerning the possible difference in the ecology of gammarids between the 2 subunits. The ability of infected hosts to undergo a large phenotypic alteration such as a change of microhabitat depends in theory on the capacity for several traits to accommodate the novelty through phenotypic plasticity. Given the important ecological differences between living at the surface or near the bottom (e.g. light, current, salinity, temperature, food quality and quantity, risk of predation, density, levels of intra and inter-specific competition), we may thus expect traits other than those directly linked to the behavioural manipulation to display substantial variation between individuals from the 2 subunits. By comparing several variables (intermoult duration, survival, number of juveniles produced, levels of energetic reserves and sizeassortative pairing) between gammarids from the 2 compartments, the purpose of this study was to explore the idea that manipulative parasites, through their effects on host phenotypes, split host populations in subunits of individuals with different biological characteristics. We also discuss our results in relation to several aspects of the reproductive biology in amphipods.

\section{MATERIALS AND METHODS}

Experimental procedure. During March 2004, a large sample (i.e. 1 large replicate) of pairs of Gammarus insensibilis in precopula was randomly collected following the methodology described in Thomas et al. (1995b) in the brackish lagoon of Thau (southern France, $43^{\circ} 25^{\prime} \mathrm{N}, 3^{\circ} 35^{\prime} \mathrm{E}$ ). Pairs involving infected males were identified in the field through the aberrant surface behaviour induced by the parasite. Assuming that assortative pairing based on infection status predominated in the field (Thomas et al. 1995b, 1996a), we expected that we obtained 200 uninfected pairs and 154 infected ones. Because of the behavioural alterations induced by Microphallus papillorobustus on its intermediate host, infected individuals were probably more likely to be collected than uninfected ones (Helluy 1983). This phenomenon was likely to generate a bias when calculating the prevalence of infection in the population (not done). However, for the other variables under study, there was no reason to believe that a bias would be induced by the differential probability 
capture of infected and uninfected gammarids. In the laboratory (Station Méditerranéenne de l'Environnement du littoral, Sète), pairs were kept individually in small plastic cups (diameter $2 \mathrm{~cm}$, height $5 \mathrm{~cm}$ ) filled with constantly aerated water from the Thau's lagoon $\left(18^{\circ} \mathrm{C}, 38 \%\right)$ until females moulted and mating occurred. After insemination (when pairs dissociate), males of each pair were sacrificed by exposure to $-80^{\circ} \mathrm{C}$ for a few seconds. Body length was measured (from head to tip of telson) and the head was dissected in order to count cerebral metacercariae of M. papillorobustus. Metacercariae of this trematode are permanent ovoid cysts $(270 \times 350 \mu \mathrm{m}$, Rebecq 1964) located within the amphipod brain (Helluy 1983). In the gammarid population, there was another trematode (Maritrema subdolum) sometimes encysted in the abdominal musculature (Thomas 1996). However, in the present study the prevalence of $M$. subdolum was negligible (only $2 \%$ ). In addition, several studies have demonstrated that this parasite has no significant effect on G. insensibilis behaviour, or on its life history traits (survival, fecundity, intermoult duration) (Helluy 1981, Thomas 1996, Thomas et al. 1998b). Other authors, such as Meissner \& Bick (1999) and Mouritsen \& Jensen (1997) have demonstrated a different effect on the amphipod Corophium volutator. The abdomen of each male was then dried on an absorbent paper before being frozen individually in a $1.5 \mathrm{ml}$ Eppendorf tube in liquid nitrogen, and finally transferred after $2 \mathrm{~h}$ to $\mathrm{a}-80^{\circ} \mathrm{C}$ freezer until energy reserve analyses were completed (within $3 \mathrm{mo}$ ).

Females were kept in the laboratory (in the same cup) under natural photoperiod conditions (10 h light: $14 \mathrm{~h}$ dark) and with an excess of fish food (Tetra Ani Min). The cups were examined daily. When a female died before the next moult, we recorded its survival (the number of days she lived in the laboratory conditions), as well as the number of juveniles that were able to leave the female brood pouch. For females that did not die, the end of the experiment corresponded to the next moult. We recorded the intermoult duration as well as the total number of viable juveniles that left the female brood pouch during the intermoult. These females were then preserved in alcohol $70 \% \mathrm{EtOH}$ (v/v). Body length was (from head to tip of telson) and dissected in order to count cerebral metacercariae of Microphallus papillorobustus.

Energy reserve analyses. Extraction: Glucose, glycogen and lipids were extracted from the frozen abdomens of gammarids. Abdomens were placed in a $1.5 \mathrm{ml}$ tube and crushed on ice with an eppendorf pestle. We then added $200 \mu \mathrm{H}_{2} \mathrm{O}$ to each tube. After adding $200 \mu \mathrm{l}$ of chloroform, each tube was vortexed and then centrifuged at $13000 \mathrm{rpm}$ for $10 \mathrm{~min}$ at $4^{\circ} \mathrm{C}$. The upper aqueous phase (sugars) was transferred to a new $1.5 \mathrm{ml}$ tube (tube A) and the lower chloroform phase (lipids) to a $5 \mathrm{ml}$ glass tube (tube B). The same procedure was repeated on the solid interface. The new aqueous phase was pooled in tube $\mathrm{A}$ and the new chloroform phase in tube B (final volume for each phase: $2 \times 200 \mu \mathrm{l}$ ).

Hydrolysis of glycogen into glucose: An aliquot of $100 \mu \mathrm{l}$ (for gammarid size > $15.4 \mathrm{~mm}$ ) or $160 \mu \mathrm{l}$ (for gammarid size $<15.4 \mathrm{~mm}$ ) of tube A was pipetted and $2 \mu \mathrm{l}$ of amyloglucosidase $\left(14 \mathrm{U} \mathrm{mg}^{-1}\right.$ ) (Roche) enzyme and $18 \mu \mathrm{l}$ of $2 \mathrm{M}$ sodium acetate buffer ( $\mathrm{pH}$ 4.6) were added to this aliquot; the final volume was adjusted to $200 \mu \mathrm{l}$ with $\mathrm{H}_{2} \mathrm{O}$. Tubes were incubated for $15 \mathrm{~min}$ at $37^{\circ} \mathrm{C}$, and then placed on ice.

Glucose analysis: As before, aliquots (100 or $160 \mu \mathrm{l})$ from tube A were completed to a final volume of $200 \mu \mathrm{l}$ with $\mathrm{H}_{2} \mathrm{O}$. The glucose and glycogen hydrolysats were analyzed using a modified method of glucose oxidase/peroxidase (Trinder 1969). One $\mathrm{ml}$ of commercial kit glucose RTU (bioMérieux) was added to each tube. The tubes were vortexed and incubated for $10 \mathrm{~min}$ at $37^{\circ} \mathrm{C}$. The optical density (OD) was read on a $250 \mu \mathrm{l}$ aliquot of reaction mixture at $492 \mathrm{~nm}$ on 2 wells of a 96 wells microplate in a TECAN sunrise microplate reader using Magellan software. The final value used to calculate the sample concentration of glucose was the mean of the OD obtained from the duplicates. The glucose content of each sample was determined from a calibration curve constructed using 0 (blank), 1, 2.5, 5, $10,25,50$ and $100 \mu \mathrm{l}$ of a standard glucose solution $\left(1 \mathrm{mg} \mathrm{ml}^{-1}\right.$ ) in a final $\mathrm{H}_{2} \mathrm{O}$ volume of $200 \mu \mathrm{l}$, treated in the same manner as the samples. The glycogen content was the result of the concentration obtained for the samples hydrolyzed (free glucose + glycogen hydrolyzed into glucose) minus the concentration of free glucose. The glucose and glycogen concentrations in $\mu \mathrm{g}$ per gammarid were obtained by multiplying the glucose and glycogen concentrations by 4 or by 2.5 depending on aliquot volume used $(100 \mu \mathrm{l}$ or $160 \mu \mathrm{l})$. The total extract volume for each gammarid was $400 \mu \mathrm{l}$.

Lipid analysis: Lipid analysis was based on a variation of the sulphuric acid-vanillin method used by Zöllner \& Kirsch (1962). The B tubes were placed in a heating water bath to evaporate the solvent until a final volume of 50 to $100 \mu \mathrm{l}$ was obtained. Before vortexing, $200 \mu \mathrm{l}$ of sulphuric acid was added to each tube and heated for $10 \mathrm{~min}$ at $92^{\circ} \mathrm{C}$. Three $\mathrm{ml}$ of vanillinphosphoric reagent was added and the tubes were vortexed to allow a reddish colour to develop. The colour is stable from 5 to $30 \mathrm{~min}$ and then slowly fades. The optical density was read on a $250 \mu \mathrm{l}$ aliquot of reaction mixture at $492 \mathrm{~nm}$ on 2 wells of a 96 wells microplate in a TECAN sunrise microplate reader using Magellan software. The final value used to calculate the gam- 
marid concentration of lipid was the mean of the OD obtained from the duplicates. The concentration ( $\mu \mathrm{g} / \mathrm{gammarid}$ ) was read directly from a calibration curve constructed using 0 (blank), 25, 50, 75, 100, 125, $250,175 \mu \mathrm{l}$ of a standard vegetable oil solution $\left(1 \mathrm{mg} \mathrm{ml}^{-1}\right)$ in a final $400 \mu \mathrm{l}$ volume of chloroform in $5 \mathrm{ml}$ glass tubes. The standards were treated in the same time and in the same manner as the samples.

Data analysis. All statistical tests were performed following Sokal \& Rohlf (1981), Siegel \& Castellan (1988) and Zar (1999). In many cases, an overall analysis including all obvious factors rather than subset analyses was impossible because of variance heterogeneity and unbalanced data. When data deviated from normality and/or did not fit a normal distribution after transformation, we used non-parametric statistics instead of parametric ones. Post hoc comparisons were performed according to Zar (1999), with a significance level of $p<0.05$. All tests were 2-tailed. Throughout the paper, values given are mean \pm SE. Results were considered significant at the $5 \%$ level.

\section{RESULTS}

\section{Parasitism and pair formation}

Among the 354 pairs, the null hypothesis of random pair formation with respect to the presence/absence of parasites was rejected (Table $1, \chi^{2}=73.7, \mathrm{df}=1, \mathrm{p}<$ 0.0001). As expected, homogamic pairs (UU: uninfected male-uninfected female; II: infected maleinfected female) were over-represented (73\%). Among the 2 possible underrepresented heterogamic pairs, the combination IU (infected male-uninfected female) was less underrepresented (partial $\chi^{2}=15.1$ ) than the combination UI (uninfected male-infected female) (partial $\chi^{2}=20.5$ ). However, when considering bottom and surface individuals separately, the null hypothesis of random pairing according to the presence/absence of parasites could not be rejected (surface: $\chi^{2}=2.44$, $\mathrm{df}=1, \mathrm{p}=0.12$; bottom $\chi^{2}=0.151$, df $=1, \mathrm{p}=0.70$ ). There was no significant relationship between male and female parasite load in II pairs (Spearman rank order correlation coefficient $r_{s}=-0.03, n=94, p=0.77$ ). The pattern of distribution between the surface and the bottom was significantly different between pair categories (Fig. 1, Fisher exact test on table $\mathrm{r} \times \mathrm{k}, \mathrm{p}<$ 0.0001, the comparison IU versus II did not remain significant after Sequential Bonferroni correction). Logistic regressions indicated that, on average, the parasitic status of a given individual remained a good predictor of the subunit to which it belonged (surface vs. bottom) ( $p<0.0001$, for both males and females).

\section{Size and parasitic load}

The mean body size of males was not significantly different between the different pair categories (Table 2a, ANOVA, $F_{3,347}=0.30, \mathrm{p}=0.83$ ). However, for females, there was a significant difference (Table 2a, ANOVA, $F_{3,347}=8.75, \mathrm{p}<0.0001$ ), with females from uninfected pairs UU being the largest and those from infected pairs II the smallest. There was no significant difference between the mean parasite load of infected males from IU and II pairs (Table 2b, Mann-Whitney $U$-test, $Z=-1.26$, $p=0.21$, nor between that of females from UI and II pairs (Table 2b, Mann-Whitney $U$-test, $Z=-1.70, p=0.09$ ).

\section{Survival}

The proportion of infected and uninfected females, which died before reaching the next moult was not significantly different (infected females: $31 \%$, uninfected females $33 \%$, Fisher exact test, $p=0.72$ ). No significant difference was detected between the mortality of the females belonging to different pair categories (UU: $34 \%$, II: $28.7 \%$, IU: $30 \%$, UI: $36 \%$, Fisher exact test on table $\mathrm{r} \times \mathrm{k}, \mathrm{p}=0.74$ ).

\section{Number of juveniles}

The number of viable juveniles that were produced in both infected and uninfected females was significantly influenced by the survival rate of females to

Table 1. Observed versus expected values (under the assumption of random pairing between individuals) for pairs of Gammarus insensibilis, uninfected (U) or infected (I) with Microphallus papillorobustus, collected in the field

\begin{tabular}{|c|c|c|c|c|}
\hline & \multicolumn{4}{|c|}{ Pairs } \\
\hline & $\sigma^{\prime \prime} U \times \propto$ & $\sigma^{\prime \prime} \mathrm{I} \times \phi$ & $\sigma^{\prime} \mathrm{U} \times o \mathrm{I}$ & $\sigma^{\prime} \mathrm{I} \times \stackrel{+}{ } \mathrm{U}$ \\
\hline Observed & 163 & 94 & 35 & 60 \\
\hline Expected & 126.4 & 56.2 & 70.2 & 98.2 \\
\hline
\end{tabular}

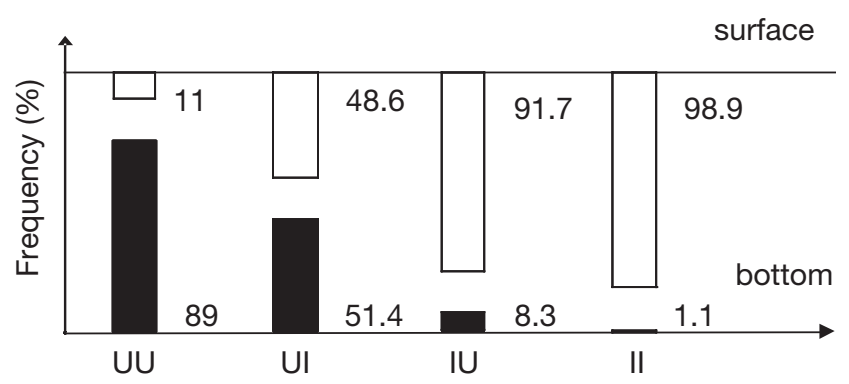

Fig. 1. Gammarus insensibilis infected with Microphallus papillorobustus. Frequency (\%) of captures of the different pair categories UU, UI, IU and II at the surface or at the bottom (codes defined in Table 1 legend) 
Table 2. Gammarus insensibilis infected with Microphallus papillorobustus. Biological characteristics (mean $\pm \mathrm{SE}$ ) of individuals within pair categories

\begin{tabular}{|c|c|c|c|c|}
\hline & \multicolumn{4}{|c|}{ Pairs } \\
\hline & $\sigma^{\prime \prime} U \times q U$ & $\mathrm{o}^{7} \mathrm{I} \times \mathrm{\varphi}^{\mathrm{I}}$ & $\mathrm{O}^{71} \mathrm{U} \times \mathrm{oI}$ & $\sigma^{7} \mathrm{I} \times \mathrm{Q} U$ \\
\hline $\begin{array}{l}\text { a) Male size } \\
(\mathrm{mm})\end{array}$ & $\begin{array}{c}21.34 \pm 0.20 \\
N=162\end{array}$ & $\begin{array}{c}21.23 \pm 0.26 \\
\mathrm{~N}=94\end{array}$ & $\begin{array}{c}21.18 \pm 0.40 \\
N=35\end{array}$ & $\begin{array}{c}21.60 \pm 0.29 \\
N=60\end{array}$ \\
\hline $\begin{array}{l}\text { Female size } \\
(\mathrm{mm})\end{array}$ & $\begin{array}{c}12.38 \pm 0.13 \\
\mathrm{~N}=163\end{array}$ & $\begin{array}{c}11.28 \pm 0.19 \\
\mathrm{~N}=94\end{array}$ & $\begin{array}{c}12.02 \pm 0.34 \\
\mathrm{~N}=34\end{array}$ & $\begin{array}{c}11.70 \pm 0.21 \\
\mathrm{~N}=60\end{array}$ \\
\hline $\begin{array}{l}\text { b) Male parasite } \\
\text { load }\end{array}$ & - & $\begin{array}{c}1.83 \pm 0.19 \\
\mathrm{~N}=94\end{array}$ & - & $\begin{array}{c}1.82 \pm 0.36 \\
\mathrm{~N}=60\end{array}$ \\
\hline $\begin{array}{l}\text { Female parasite } \\
\text { load }\end{array}$ & - & $\begin{array}{c}3.19 \pm 0.40 \\
N=94\end{array}$ & $\begin{array}{c}2.26 \pm 0.69 \\
\mathrm{~N}=35\end{array}$ & - \\
\hline $\begin{array}{l}\text { c) Number } \\
\text { of juveniles* }\end{array}$ & $\begin{array}{c}45.76 \pm 3.42 \\
\mathrm{~N}=105\end{array}$ & $\begin{array}{c}28.81 \pm 3.00 \\
N=67\end{array}$ & $\begin{array}{c}37.68 \pm 6.51 \\
N=22\end{array}$ & $\begin{array}{c}28.81 \pm 6.03 \\
\mathrm{~N}=39\end{array}$ \\
\hline $\begin{array}{l}\text { d) Intermoult* } \\
\text { duration (d) }\end{array}$ & $\begin{array}{c}14.32 \pm 0.18 \\
\mathrm{~N}=105\end{array}$ & $\begin{array}{c}14.43 \pm 0.21 \\
\mathrm{~N}=67\end{array}$ & $\begin{array}{c}14.27 \pm 0.34 \\
\mathrm{~N}=22\end{array}$ & $\begin{array}{c}13.54 \pm 0.19 \\
\mathrm{~N}=39\end{array}$ \\
\hline $\begin{array}{l}\text { e) Male lipid } \\
\text { content }(\mu \mathrm{g})\end{array}$ & $\begin{array}{c}95.93 \pm 3.28 \\
N=163\end{array}$ & $\begin{array}{c}101.26 \pm 3.90 \\
\mathrm{~N}=94\end{array}$ & $\begin{array}{c}91.24 \pm 4.77 \\
\mathrm{~N}=35\end{array}$ & $\begin{array}{c}103.66 \pm 4.35 \\
N=60\end{array}$ \\
\hline $\begin{array}{l}\text { Male glucose } \\
\text { content }(\mu g)\end{array}$ & $\begin{array}{c}161.22 \pm 6.52 \\
N=163\end{array}$ & $\begin{array}{c}145.19 \pm 8.46 \\
N=94\end{array}$ & $\begin{array}{c}176.84 \pm 13.36 \\
\mathrm{~N}=35\end{array}$ & $\begin{array}{c}154.80 \pm 12.24 \\
N=60\end{array}$ \\
\hline $\begin{array}{l}\text { Male glycogen } \\
\text { content }(\mu \mathrm{g})\end{array}$ & $\begin{array}{c}65.95 \pm 3.48 \\
N=163\end{array}$ & $\begin{array}{c}110.65 \pm 5.95 \\
N=94\end{array}$ & $\begin{array}{c}5.07 \pm 8.35 \\
\mathrm{~N}=35\end{array}$ & $\begin{array}{c}102.26 \pm 6.86 \\
N=60\end{array}$ \\
\hline $\begin{array}{l}\text { f) Size assor- } \\
\text { tative pairing }\end{array}$ & $\begin{array}{c}\mathrm{N}=162 \\
\mathrm{r}^{2}=0.28 \\
\text { Slope }=0.58 \\
\mathrm{p}<0.0001\end{array}$ & $\begin{aligned} & 94 \\
& 0.27 \\
& 0.68 \\
< & 0.0001\end{aligned}$ & $\begin{array}{c}34 \\
0.26 \\
0.78 \\
<0.0001\end{array}$ & $\begin{array}{c}60 \\
0.13 \\
0.46 \\
<0.005\end{array}$ \\
\hline
\end{tabular}

\section{Intermoult duration}

Intermoult duration (Table 2d) was positively correlated with female size (ln [intermoult] $=0.21 \times \ln$ [female size] $+2.14, \mathrm{r}^{2}=0.08, \mathrm{~N}=232, \mathrm{p}<0.0001$ ). The mean intermoult duration was not significantly different between females from the different pair categories (Kruskal-Wallis ANOVA, $\chi^{2}=3.35$, df $=$ $3, p=0.34)$. However, when corrected for female size, intermoult durations were significantly different between pair categories (Kruskal-Wallis ANOVA, $\chi^{2}=21.29$, df $=3, p<0.0001$ ), with on average infected females (i.e. from UI and II pairs) having longer intermoult (positive residuals) durations than uninfected ones (negative residuals) (Fig. 3A) (post hoc comparison, comparison IU/II, $\mathrm{p}<0.05$ ). This difference was explained more by the infection status than by the habitat subunit (2-way ANOVA, infection status: $p=0.009$, subunit: $p=0.13$, interaction NS). Intermoult durations (corrected for size) were also positively correlated with the number of metacercariae per females (Fig. 3B, Spearman rank correlation, $\mathrm{r}_{\mathrm{s}}=0.29, \mathrm{~N}=232, \mathrm{p}<0$. 0001). This relationship was still significant when calculated from infected females only (Spearman rank correlation, $\mathrm{r}_{\mathrm{s}}=$ $0.31, \mathrm{~N}=88, \mathrm{p}=0.004)$. There was no significant relationship between the intermoult durations (corrected for size) and the number of juveniles (corrected for size) produced by females (Spearman rank correlation, $\mathrm{r}_{\mathrm{s}}=-0.07, \mathrm{~N}=232, \mathrm{p}=0.27$ ).

\section{Male energy reserves}

Energy reserves (lipid, glucose and glycogen) of males in the different categories are presented in Table 2e. Both glucose and lipid contents were positively correlated to male size (glucose: $\ln$ (glucose) = $1.47 \times \ln$ (male size) $+0.37, \mathrm{r}^{2}=0.065, \mathrm{~N}=351, \mathrm{p}<$ 0.0001 ; Lipids: $\ln ($ lipid $)=1.18 \times \ln ($ male size $)+0.90$, $\left.\mathrm{r}^{2}=0.12, \mathrm{~N}=351, \mathrm{p}<0.0001\right)$. Conversely, glycogen content was negatively correlated to male size (ln $($ glycogen $)=-0.65 \times \ln ($ male size $)+6.19, \mathrm{r}^{2}=0.009$, $\mathrm{N}=343, \mathrm{p}=0.08$ ). Therefore, in further analyses we used the residuals of the regression of reserves on male size (ln transformed) (i.e. energy reserves corrected for size). 


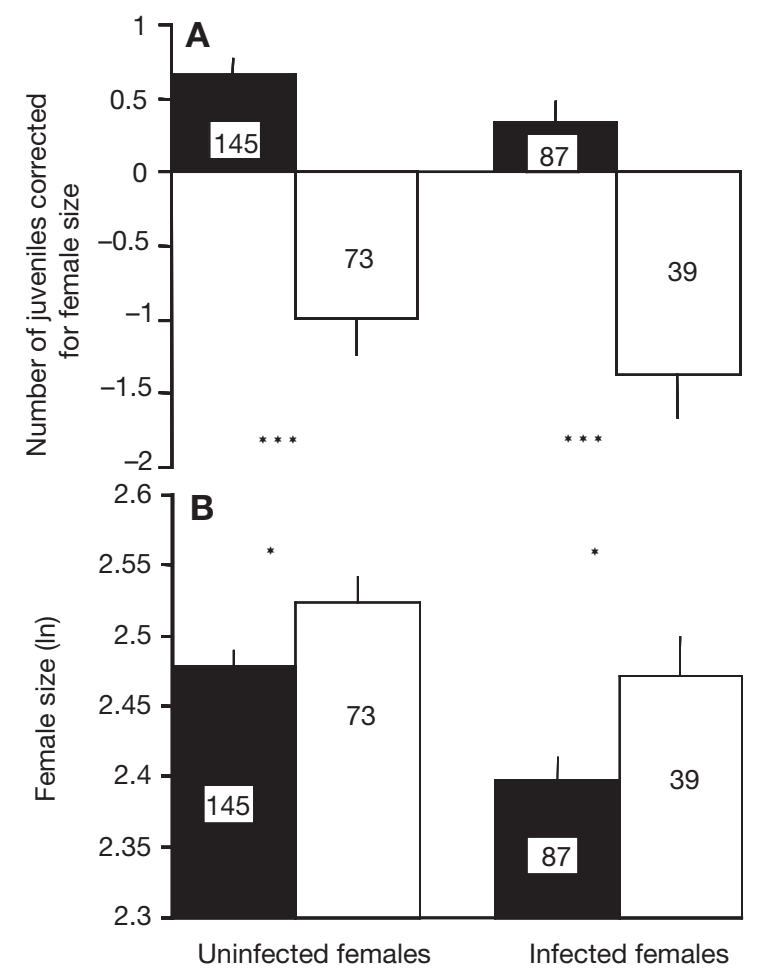

Fig. 2. Gammarus insensibilis infected with Microphallus papillorobustus. (A) Size-corrected number of juveniles produced by females $(+\mathrm{SE})$ (residuals of the relationship between number of juveniles $[\ln (x+1)]$ and female size [ln]) in relationship with parasitic status and survival (black bars: the female lived until the second moult, white bars: the female died before the second moult). (B) Female size (+SE) (ln) in relationship with infection status and survival (black bars: the female lived until the second moult, white bars: the female died before the second moult). Numbers inside bars refer to sample sizes. ${ }^{*} \mathrm{p}<0.05{ }^{* * *} \mathrm{p}<0.001$

For both lipid and glycogen contents, values were significantly higher in infected males than in uninfected ones (Mann-Whitney $U$-test, lipid: $Z=2.42, \mathrm{p}=$ 0.01; glycogen: $Z=6.44$, p < 0.0001). Conversely, for glucose content, uninfected males displayed higher values than infected ones (Mann-Whitney $U$-test, $Z=$ -2.17, $\mathrm{p}=0.03$ ). A closer examination revealed that only glycogen content was significantly different between males from the different pairing categories, with those from UU pairs displaying the smallest values (Fig. 4, Kruskal-Wallis ANOVA, $\chi^{2}=45.43$, df $=3$, p < 0.0001; post hoc comparisons, $\mathrm{p}<0.05$ for comparisons UU/IU and UU/II). To assess the possible influence of the microhabitat on energy reserves, we compared the glycogen content of males from UI pairs collected both at the surface and at the bottom. Interestingly, males from UI pairs captured at the bottom (i.e. like most UU pairs) displayed significantly lower values than those from UI pairs captured at the surface (Mann-Whitney $U$-test, $Z=2.39, \mathrm{~N} 1=18, \mathrm{~N} 2=17, \mathrm{p}=0.02$ ).

\section{Size-assortative pairing}

There was a significant positive relationship between male size and female size within pairs $\left(\mathrm{r}^{2}=0.23\right.$, $\mathrm{N}=350, \mathrm{p}<0.0001, \ln$ [female size] $=0.61 \times \ln$ [male size] + 0.60). Assortative pairing by size was still significant when observed within pair categories (Fig. 5, Table 2f), and there was no significant difference between slopes (analysis of covariance $F_{3,246}=0.72$, p = $0.54)$.

\section{Determinants of male performance}

The mean male performance (measured using the residuals of the regression of female size [ln transformed] on male size [ln transformed]) was significantly different between pair categories (KruskalWallis ANOVA, $\chi^{2}=31.61$, df $=3, \mathrm{p}<0.0001$ ), with uninfected males being paired with larger females than infected males (Fig. 6A) (post hoc comparisons, $\mathrm{p}<0.05$ for comparison UU/IU and for UU/II). However, when male performance was estimated through the number of viable descendants instead of female size (i.e. residuals of the regression of number of juveniles [ln +1 transformed] on male size [ln transformed]), differences between performances of males from different categories were much more limited (Kruskal-Wallis ANOVA, $\chi^{2}=9.08$, df $=3, p=0.03$, Fig. 6B), presumably because of the higher mortality rate of large females (see Fig. 2B).

Among infected males (i.e. IU and II pairs), the parasitic load did not significantly influence the male's sexual performance estimated either through the size of their females (female size corrected for male size) (Spearman rank order correlation coefficient, $\mathrm{r}_{\mathrm{s}}=0.04$, $\mathrm{N}=154, \mathrm{p}=0.61$ ), or through the number of juveniles (corrected for male size) (Spearman rank order correlation coefficient, $\mathrm{r}_{\mathrm{s}}=0.035, \mathrm{~N}=154, \mathrm{p}=0.67$ ).

Finally there was no significant difference between size-corrected energy reserves of males and their sexual performance estimated as before through the size of their partner or through the number of viable descendants (Spearman rank correlation $\mathrm{p}>0.05$ for all comparisons). Similarly, there was no significant link between male energy reserves (glucose, glycogen and lipid) corrected for size and the fact that their partner died or survived during the intermoult (MannWhitney $U$-test, p > 0.05 in each case). Finally, among UI pairs, the male sexual performance (estimated through female size, number of viable descendants, female survival and female parasitic load) was not significantly different between pairs from the surface and those from the bottom (Mann-Whitney $U$-test, $\mathrm{p}>0.14$ in each case). 


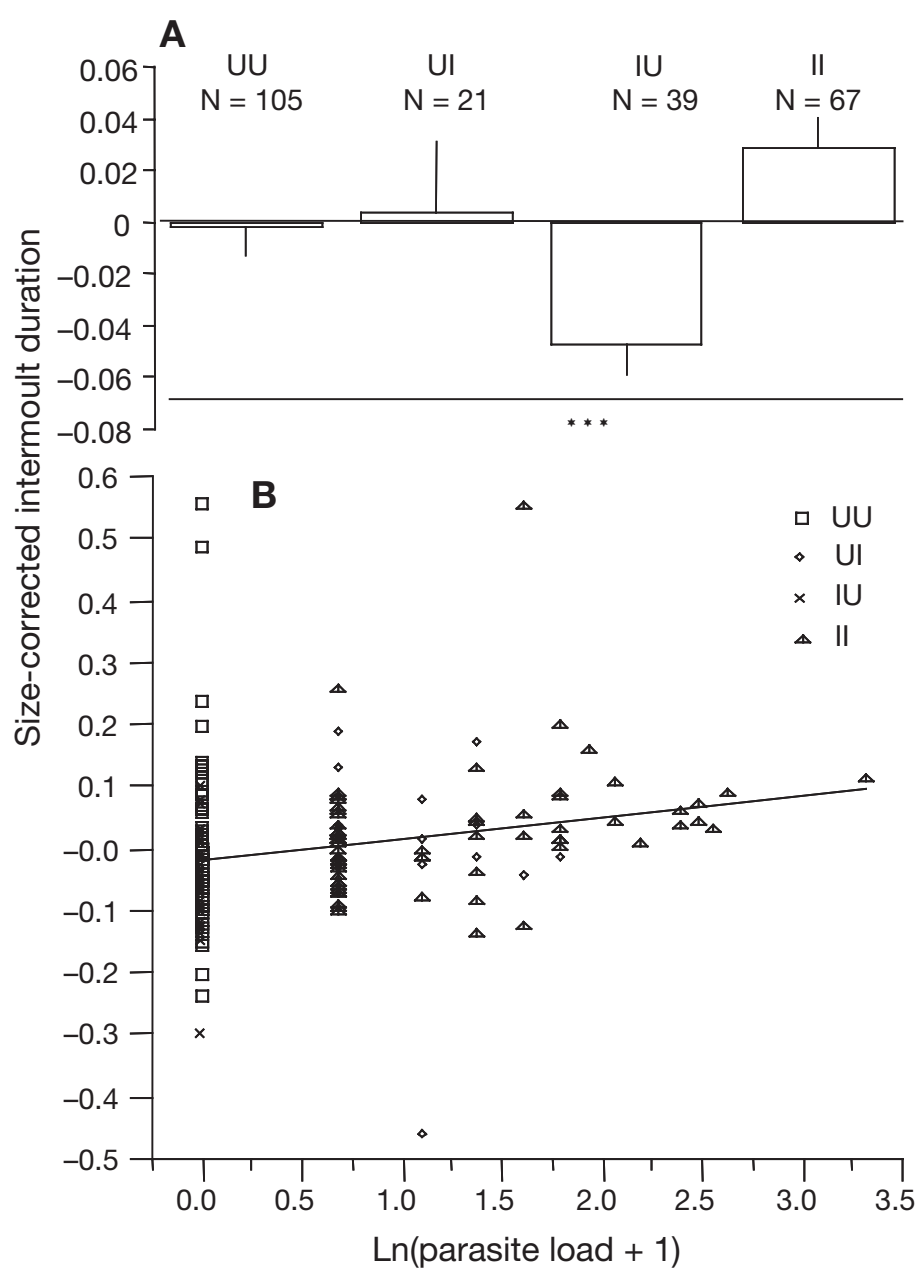

Fig. 3. Gammarus insensibilis infected with Microphallus papillorobustus. (A) Intermoult durations (corrected for size) of females from the different pair categories (U: uninfected; I: infected) $\left({ }^{* * *} \mathrm{p}<0.001\right)$. (B) Relationship between intermoult durations (corrected for size) and the number of metacercariae per female

Table 3 summarises the mean characteristics of gammarids according to their infection status (whatever their subunits) and according to the subunits they belonged (whatever their infection status). The main difference concerned the intermoult duration corrected for size, which was not significantly different $(p=0.70)$ when examined between surface and bottom females.

\section{DISCUSSION}

Population ecology and animal behaviour are 2 subjects that have developed largely in isolation, despite the widespread acceptance that they are related and the frequent acknowledgement of a need to combine them (Sutherland 1997). This work clearly supports the idea that the ecology of Gammarus insensibilis populations cannot be fully understood without acknowledging the fact that a fraction of the population harbours the manipulative parasite Microphallus papillorobustus. The most spectacular consequence of this infection is of course the spatial segregation resulting from the parasite-induced behavioural change as it actually splits the host population into 2 discrete subunits. However, by studying in more detail the biological characteristics of individuals belonging to the 2 subunits, the present work also suggests that infected gammarids are not simply normal hosts with one aberrant trait (e.g. behaviour), instead they are more deeply modified organisms with a range of alterations, some of which may favour the parasite, some of which may favour the host and some that may simply be byproducts of the parasitism.

The first interesting finding of this study is that paired gammarids were matched for the presence/ absence of Microphallus papillorobustus. Such a result obtained 9 yr after the first study showing this (Thomas et al. 1995b) not only demonstrates that this original pattern of pairing is remarkably stable over time in this gammarid population, it also supports the idea that parasite-induced spatial segregation is effective, placing the 2 subunits in relative isolation.

Hosts infected with debilitating parasites are under pressure to evolve not only ways of eliminating the parasites (host immunity in the broadest sense), but also ways of compensating for parasite effects when elimination is impossible. Hosts unable to resist infection by other means (immunological resistance and/or inducible defences) are thus favoured by selection if they partly compensate for the parasite-induced losses by adjusting their life history traits. Such host adaptive responses have been previously reported in amphipod-trematode systems: when infected by the digenean trematode Gynaecotyla aduncta, males of Corophium volutator increase their mating effort before the behavioural manipulation occurs (McCurdy et al. 2000) and young females decreased their timeto-moult, thereby decreasing their time for mating receptivity following infection by the manipulative trematode (McCurdy et al. 1999, 2001). Contrary to theoretical expectations, our results showed that females in Gammarus insensibilis did not increase the number of reproductive events by increasing moult frequency, instead they displayed a longer intermoult duration, and this phenomenon was positively correlated to the number of metacercariae (see also Thomas et al. 1996b). Given that moulting is energetically costly for crustaceans, it might be adaptive for the parasite to reduce the frequency of this event so as to enhance the host survival. Alternatively, it is possible 

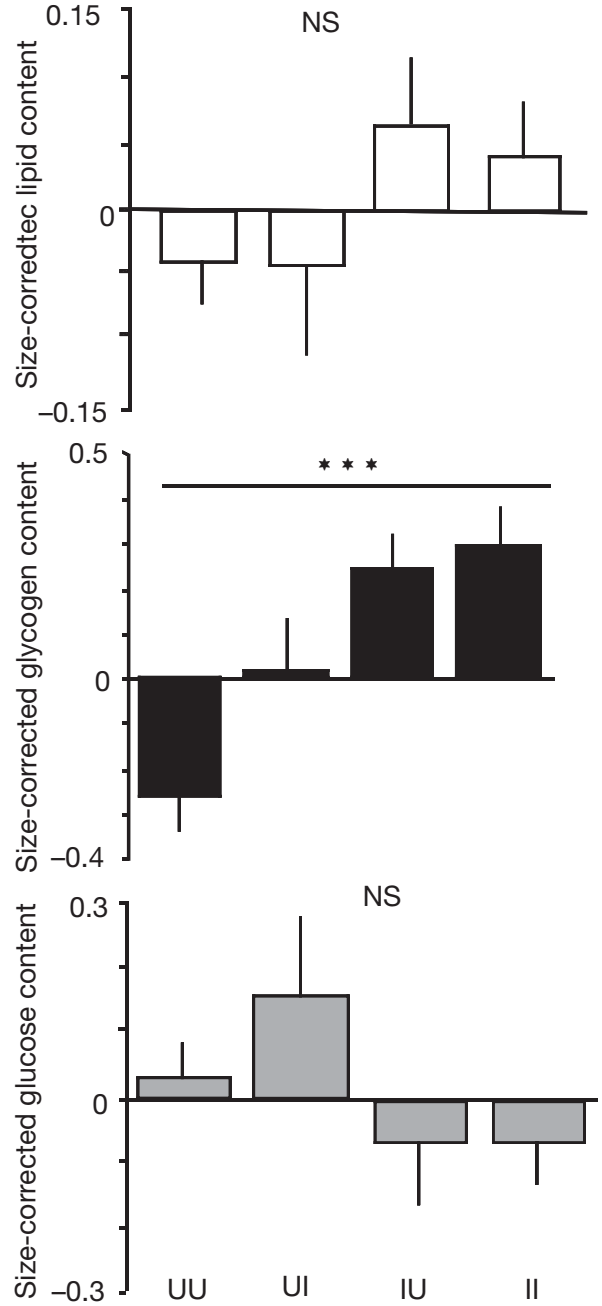

Fig. 4. Gammarus insensibilis infected with Microphallus papillorobustus. Energy reserves (lipid-, glucose- and glycogen-corrected for male size) in males from the different pair categories. ${ }^{* * *} \mathrm{p}<0.001$. U: uninfected; I: infected

that moulting time in brooding females is determined by the release of the juveniles from the brood pouch. A longer intermoult duration could indicate that the embryos of infected females take a longer time to develop. However, it remains difficult without additional data to determine whether this longer intermoult duration is adaptive for the parasite, the host or just a non-adaptive side effect of infection.

The main intriguing result obtained when analysing energy reserves was that on average, infected males had higher glycogen and lipid contents than uninfected ones. Similar results have previously been found in brine shrimps Artemia ssp. parasitized by cestodes (Amat et al. 1991) and in Gammarus pulex parasitized by acantocephalans (Plaistow et al. 2001). These parasites are phylogenetically unrelated but they evolved under similar ecological pressures for their transmission as they require the predation of the crustacea by a vertebrate predator. However, it is unclear whether these similarities illustrate a common cause or a common consequence. Plaistow et al. (2001) suggested several explanations for this pattern: (1) the parasite-modified behaviour of gammarids may increase behavioural costs by increasing the activity of the host, (2) increase in glycogen content is an indirect consequence of the increasing energetic demands of parasitized individuals or (3) higher glycogen contents in parasitized individuals is an adaptive manipulation of the host's energy reserves that either causes modified behaviour, or, alternatively furnished the increased energetic demands of parasite-modified behaviour. The fact that in our study, males from UI pairs living at the surface display higher glycogen content than those living at the bottom at least indicates that the physical presence of the parasite is not per se the only relevant variable that influenced glycogen content. However, whether this phenomenon results from the consequence of the female behaviour on the male behaviour or environmental causes is impossible to determine from these data. In addition to the hypotheses suggested by Plaistow et al. (2001), we would like to mention another possibility. Indeed, there are an increasing number of theoretical and empirical evidence suggesting that predators foraging on infected prey try to minimise the ratio cost of infection/energetic benefits (Hulscher 1973, Lafferty 1992, Poulin 1994, Lafferty 1999, Norris 1999, Hutchings et al. 2000, Thomas et al. 2000, Aeby 2002). In this context, enhancing the nutritive value of the host may be selected as a parasitic strategy to increase transmission when predators are able to discriminate among prey having different energetic values. Further experiments would be needed to determine whether the definitive hosts of Microphallus papillorobustus (several species of aquatic birds) are able to make such discriminations. Finally, the lower glucose content (representative of the energy available for current activities) in infected gammarids supports the idea that infected gammarids have an increased activity compared to uninfected ones.

Despite the smaller size of infected females compared to uninfected ones, we were unable to detect significant difference in the pattern of size-assortative pairing between the different pair categories (see also Thomas et al. 1995b). Among infected males, the parasitic load seems to have had no influence either on their sexual performance. However, an important result of this study was that large females were more likely to die during the intermoult than smaller ones, a phenomenon which directly influences the number of 


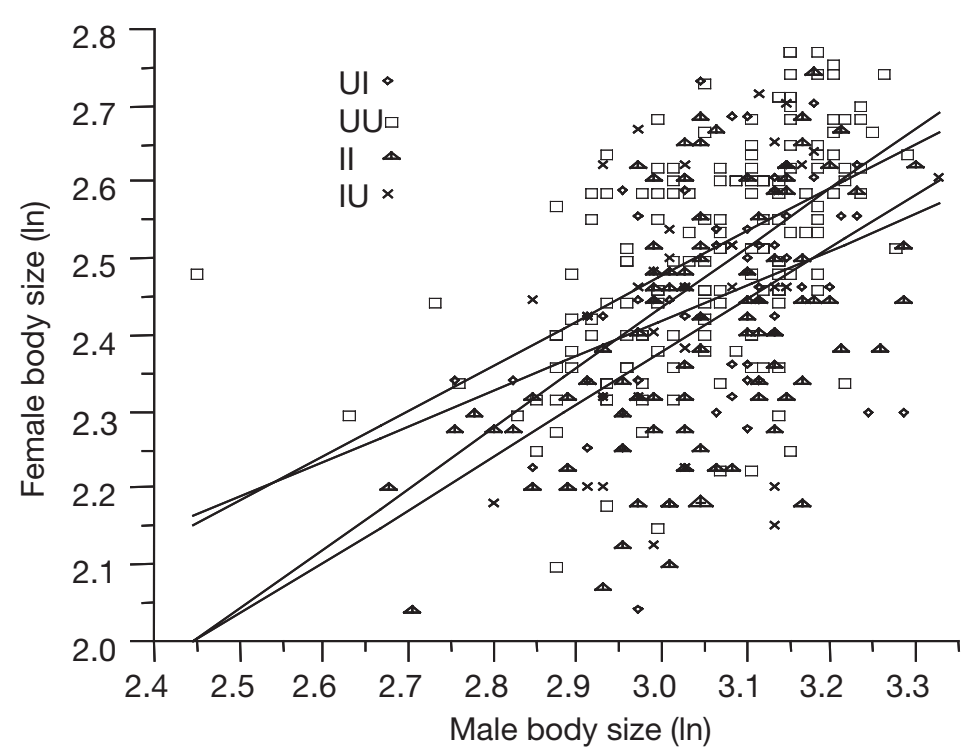

Fig. 5. Gammarus insensibilis infected with Microphallus papillorobustus. Relationship between male and female body size in UU, UI, IU, and II precopula pairs. U: uninfected; I: infected
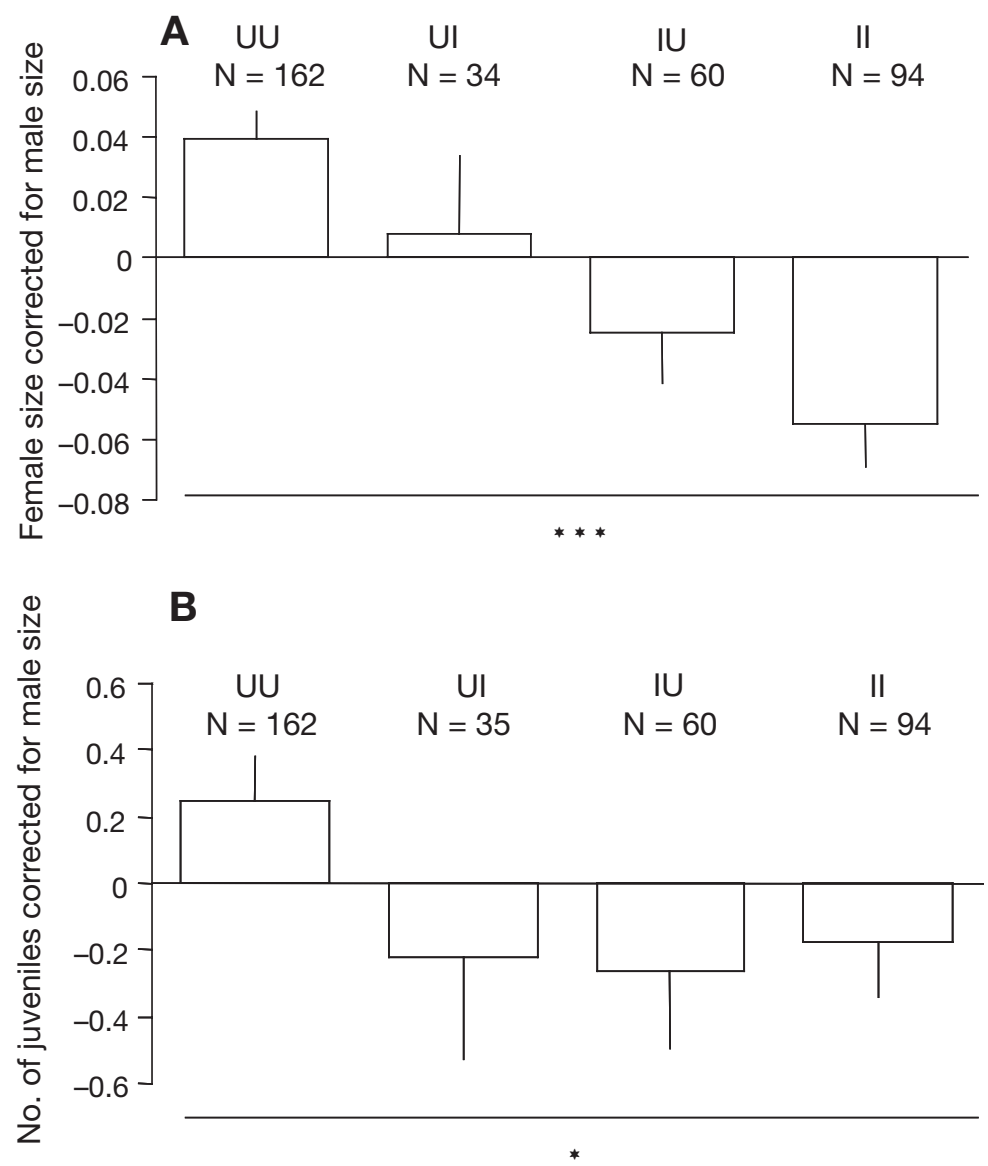

Fig. 6. Gammarus insensibilis infected with Microphallus papillorobustus. Male performance measured through (A) the residuals of female size on male size, (B) the residuals of the number of juveniles produced. ${ }^{*} \mathrm{p}<0.05_{;}{ }^{* * *} \mathrm{p}<0.001$. U: uninfected; I: infected viable juveniles produced. This result (assuming that it applies to natural conditions) is very important in the context of the breeding biology of gammaridean amphipods. It is traditionally assumed that male gammarids compete severly for access to large females because they are more fecund. If it is true that larger females are more fecund than smaller ones in most gammarid species (Hartnoll \& Smith 1978, Ward 1985, Sutcliffe 1992, 1993a,b), then we should take into account the mortality rate of females during intermoult periods, in order to get a better understanding of the fitness benefits gained by choosy males. In our system, we found that when fitness benefits of males were examined through the number of viable juveniles actually produced by their partner, differences were much less reduced than those expected after correcting for female size differences. Further studies would be necessary to determine whether differential patterns of size-dependant mortality in female gammarids contribute to the generation of spatial or temporal variation in males' pairing preferences and hence the pattern of size-assortative pairing.

In conclusion, this study demonstrated that sometimes host parasitically modified populations consist of subunits of individuals that differ for several phenotypic traits (Table 3) in addition to those most obviously altered like the behaviour. More experiments are needed to understand all the existing differences, whether they result from plastic adjustments of the hosts to novel conditions, or complex alterations of the host phenotype when parasites manipulate several traits in their hosts.

Acknowledgements. We thank P. Auzier for his technical assistance and 4 anonymous referees for comments on an earlier version of this manuscript. We thank the Station Méditerranéenne de l'Environnement du Littoral (Sète) and F. Bonhomme for allowing us to use the field station. F.P. thanks the Research Ministry of France for a scholarship. This work was supported by an ACI CNRS grant to F.T . 
Table 3. Gammarus insensibilis infected with Microphallus papillorobustus. Summary of the main biological differences between uninfected versus infected gammarids and between bottom versus surface gammarids (probabilities come from Mann-Whitney $U$-tests, ${ }^{*}$ : probabilities that remain significant after Bonferroni corrections. NS: not significant

\begin{tabular}{|c|c|c|c|c|}
\hline & $\begin{array}{c}\text { Parasitic status } \\
\text { Uninfected (U) vs. Infected (I) }\end{array}$ & $\mathrm{p}$ & $\begin{array}{c}\text { Subunits } \\
\text { Bottom (B) vs. Surface (S) }\end{array}$ & $\mathrm{p}$ \\
\hline Male Size & NS & & NS & \\
\hline Female size & $\mathrm{U}>\mathrm{I}$ & $0.0005^{*}$ & $\mathrm{~B}>\mathrm{S}$ & $<0.0001^{*}$ \\
\hline Female survival & NS & & NS & \\
\hline Female intermoult duration & NS & & NS & \\
\hline Intermoult duration (corrected for size) & $\mathrm{U}<\mathrm{I}$ & $<0.0001^{*}$ & NS & \\
\hline Number of juveniles/female & $\mathrm{U}>\mathrm{I}$ & 0.03 & $\mathrm{~B}>\mathrm{S}$ & 0.01 \\
\hline Number of juveniles (corrected for size) & NS & & NS & \\
\hline Glycogen content (male) & $\mathrm{U}<\mathrm{I}$ & $<0.0001^{*}$ & $\mathrm{~B}<\mathrm{S}$ & $<0.0001^{*}$ \\
\hline Lipid content (male) & $\mathrm{U}<\mathrm{I}$ & 0.015 & NS & \\
\hline Glucose content (male) & $\mathrm{U}>\mathrm{I}$ & 0.03 & NS & \\
\hline \multicolumn{5}{|l|}{ Male sexual performance: } \\
\hline - size of the female & $\mathrm{U}>\mathrm{I}$ & $<0.0001^{*}$ & $\mathrm{~B}>\mathrm{S}$ & $<0.0001^{*}$ \\
\hline - number of juveniles & $\mathrm{U}>\mathrm{I}$ & 0.005 & $\mathrm{~B}>\mathrm{S}$ & 0.01 \\
\hline
\end{tabular}

\section{LITERATURE CITED}

Aeby GS (2002) Trade-offs for the butterflyfish, Chaetodon multicinctus, when feeding on coral prey infected with trematode metacercariae. Behav Ecol Sociobiol 52:158-165

Agnew P, Bedhomme S, Haussy C, Michalakis Y (1999) Age and size at maturity of the mosquito Culex pipiens infected by the microsporidian parasite Vavraia culicis. Proc R Soc Lond B 266:947-952

Amat F, Gozalbo JC, Navarro JC, Hontoria F, Varo I (1991) Some aspects of Artemia biology affected by cestode parasitism. Hydrobiologia 212:29-44

Anderson RC (1972) The ecological relationships of meningeal worm and native cervids in North America. J Wildl Dis 8:304-310

Anderson RM, Gordon DM (1982) Processes influencing the distribution of parasite numbers within host populations with special emphasis on parasite-induced host mortalities. Parasitology 85:373-398

Brun B (1971) Variations intraspécifiques et spéciation chez deux espèces de gammares d'eau saumâtre du groupe Gammarus locusta (Crustacés, Amphipodes). PhD thesis, Université de Provence, Marseille

Clayton DH (1991) The influence of parasites on host sexual selection. Parasitol Today 7:329-334

Combes C (1996) Parasites, biodiversity and ecosystem stability. Biodivers Conserv 5:953-962

Combes C (1998) Parasitism: the Ecology and Evolution of intimate interactions. The University of Chicago Press, London

Forbes MRL (1993) Parasitism and host reproductive effort. Oikos 67:444-450

Hamilton WD, Zuk M (1982) Heritable true fitness and bright birds: a role for parasites. Science 218:384-387

Hartnoll RG, Smith SM (1978) Pair formation and the reproductive cycle in Gammarus duebeni. J Nat Hist 12: 501-511

Helluy S (1981) Parasitisme et comportement. Etude de la métacercaire de Microphallus papillorobustus (Rankin 1940) et de son influence sur les gammares. PhD thesis, USTL Montpellier

Helluy S (1983) Relations hôtes-parasites du trématode Microphallus papillorobustus (Rankin 1940). II. Modifications du comportement des Gammarus hôtes intermedi- aires et localisation des métacercaires. Ann Parasitol Hum Comp 58:1-17

Helluy S (1984) Relations hôtes-parasites du trématode Microphallus papillorobustus (Rankin 1940). III. Facteurs impliqués dans les modifications du comportement des Gammarus hôtes intermediaires et tests de prédation. Ann Parasitol Hum Comp 59:41-56

Hochberg ME, Michalakis Y, de Meeüs T (1992) Parasitism as a constraint on the rate of life-history evolution. J Evol Biol 5:491-504

Holt R, Boulinier T (2005) Ecosystems and Parasitism: the spatial dimension. In: Thomas F, Renaud F, Guégan JF (eds) Parasitism and ecosystems. Oxford University Press, New York, p 68-89

Howard RD, Minchella DJ (1990) Parasitism and mate competition. Oikos 58:120-122

Hulscher JB (1973) Burying-depth and trematode infection in Macoma balthica. Neth J Sea Res 6:141-156

Hutchings MR, Kyriazakis I, Papachristou TF, Gordon IJ, Jackson F (2000) The herbivores' dilemma: trade-offs between nutrition and parasitism in foraging decisions. Oecologia 124:242-251

Lafferty KD (1992) Foraging on prey that are modified by parasites. Am Nat 140:854-867

Lafferty KD (1993) The marine snail Cerithidea californica, matures at smaller sizes where parasitism is high. Oikos 68:3-11

Lafferty KD (1999) The evolution of trophic transmission. Parasitol Today 15:111-115

McCurdy DG, Forbes MR, Boates JS (1999) Testing alternative hypotheses for variation in amphipod behaviour and life history in relation to parasitism. Int J Parasitol 29: 1001-1009

McCurdy DG, Forbes MR, Boates JS (2000) Male amphipods increase their mating effort before behavioural manipulation by trematodes. Can J Zool 78:606-612

McCurdy DG, Boates JS, Forbes MR (2001) An empirical model on the optimal timing of reproduction for female amphipods infected by trematodes. J Parasitol 87:24-30

Meissner K, Bick A (1999) Mortality of Corophium volutator (Amphipoda) causes by infestation with Maritrema subdolum (Digenea, Microphallidae). Dis Aquat Org 35: $47-52$

Michalakis Y, Hochberg ME (1994) Parasitic effects on host 
life-history traits: a review. Parasite 1:191-194

Moller AP (1997) Parasitism and the evolution of host lifehistory traits. In: Clayton DH, Moore J (eds) Host-parasite evolution: general principles and avian models. Oxford University Press, New York, p 105-127

Moller AP (2005) Parasitism and the regulation of host populations. In: Thomas F, Renaud F, Guégan JF (eds) Parasitism and ecosystems. Oxford University Press, New York

Moore J (2002) Parasites and the behavior of animals. Oxford Series in Ecology and Evolution, Oxford University Press, New York, p 43-53

Moore SL, Wilson K (2002) Parasites as a viability cost of sexual selection in natural populations of mammals. Science 297:2008-2009

Mouritsen KN, Jensen KT (1997) Parasite transmission between soft-bottom invertebrates: temperature mediated infection rates and mortality in Corophium volutator. Mar Ecol Prog Ser 151:123-134

Norris K (1999) A trade-off between energy intake and exposure to parasites in oystercatchers feeding on a bivalve mollusc. Proc R Soc Lond B 266:1703-1709

Plaistow SJ, Troussard JP, Cézilly F (2001) The effect of the acanthocephalan parasite Pomphorhynchus laevis on the lipid and glycogen content of its intermediate host Gammarus pulex. Int J Parasitol 31:346-351

Poulin R (1994) The evolution of parasite manipulation of host behaviour: a theoretical analysis. Parasitology 109: 109-118

Poulin R (1998) Evolutionary ecology of parasites: from individuals to communities. Chapman \& Hall, London

Poulin R, Thomas F (1999) Phenotypic variability induced by parasites: extent and evolutionary implications. Parasitol Today 15:28-32

Rebecq J (1964) Recherches systématiques, biologiques et écologiques sur les formes larvaires de quelques Trématodes de Camargue. PhD thesis Faculté de Sciences de Marseille

Richner H, Triplet F (1999) Ectoparasitism and the trade-off between current and future reproduction. Oikos 86: 535-538

Rousset F, Thomas F, de Meeüs T, Renaud F (1996) Inference of parasite-induced host mortality from distributions of parasite loads. Ecology 77:2203-2211

Siegel S, Castellan NJ (1988) Nonparametric statistics for the behavioral sciences, 2nd edn. McGraw-Hill, New York

Sokal RR, Rohlf FJ (1981) Biometry, 2nd edn. WH Freeman, New York

Sutcliffe DW (1992) Reproduction in Gammarus (Crustacea:Amphipoda): basic reproductive processes. Freshw Forum 2:102-128

Sutcliffe DW (1993a) Reproduction in Gammarus (Crustacea: Amphipoda): male strategies. Freshw Forum 3:97-109

Sutcliffe, DW (1993b) Reproduction in Gammarus (Crustacea: Amphipoda): female strategies. Freshw Forum 3:26-64

Sutherland WJ (1997) From individual behaviour to population ecology. Oxford University Press, New York

Editorial responsibility: Otto Kinne (Editor-in-Chief), Oldendorf/Luhe, Germany
Thomas F (1996) Conséquences écologiques et évolutives des interactions hôtes (Gammarus insensibilis)- parasites (Microphallus, Maritrema). PhD thesis, Universite Montpellier II

Thomas F, Renaud F, Rousset F, Cézilly F, de Meeüs T (1995a) Differential mortality of two closely related host species induced by one parasite. Proc R Soc Lond B 260:349-352

Thomas F, Renaud F, Derothe JM, Lambert A, de Meeüs T, Cézilly F (1995b) Assortative pairing in Gammarus insensibilis (Amphipoda) infected by a trematode parasite. Oecologia 104:259-264

Thomas F, Renaud F, Cézilly F (1996a) Assortative mating by parasitic prevalence in Gammarus insensibilis (Amphipoda): patterns and processes. Anim Behav 52:683-690

Thomas F, Verneau O, Santalla F, Cézilly F, Renaud F (1996b) The influence of intensity of infection by a trematode parasite on the reproductive biology of Gammarus insensibilis (Amphipoda). Int J Parasitol 26:1205-1209

Thomas F, Renaud F, de Meeüs T, Poulin R (1998a) Manipulation of host behaviour by parasites: ecosystem engineering in the intertidal zone. Proc R Soc Lond B 265: 1091-1096

Thomas F, Villa M, Montoliu I, Santalla F, Cézilly F, Renaud F (1998b) Analyses of a debilitating parasite (Microphallus papillorobustus, Trematoda) and his 'hitch-hiker' parasite (Maritrema subdolum, Trematoda) on their intermediate host (Gammarus insensibilis, Amphipoda) survival. J Helminthol Soc Wash 65:1-5

Thomas F, Poulin R, de Meeüs T, Guégan JF, Renaud F (1999) Parasites and ecosystem engineering: what roles could they play? Oikos 84:167-171

Thomas F, Poulin R, Guégan JF, Mikalakis Y, Renaud F (2000) Are there pros as well as cons to being parasitized? Parasitol Today 16:533-536

Thomas F, Adamo S, Moore J (2005a) Parasitic manipulation: where are we and where should we go? Behav Process 68:185-190

Thomas F, Bonsall M, Dobson AP (2005b) Parasitism, biodiversity and conservation. In: Thomas F, Renaud F, Guégan JF (eds) Parasitism and Ecosystems. Oxford University Press, New York, p 129-139

Torchin ME, Lafferty KD, Dobson AP, McKenzie VJ, Kuris AM (2003) Introduced species and their missing parasites. Nature 421:628-630

Trinder P (1969) Determination of glucose in blood using glucose oxidase with an alternative oxygen acceptor. Ann Clin Biochem 6:24

Ward PI (1985) The breeding behaviour of Gammarus duebeni. Hydrobiologia 121:45-50

Zar JH (1999) Biostatistical analysis. Prentice-Hall, Englewood Cliffs, NJ

Zöllner N, Kirsch K (1962) Uber die quantitative Bestimmung von Lipoiden (mikromethode) mittels der vielen naturlichen Lipoiden (allen bekannten Plasmalipoiden) gemeinsamen Sulphospho-vanillin-Reaktion. Z Gesamt Exp Med 135:545

Submitted: April 24, 2004; Accepted: March 19, 2005

Proofs received from author(s): July 29, 2005 